\title{
Estimation of Demand Systems Based on Elasticities of Substitution
}

by Germán Coloma (CEMA University, Buenos Aires, Argentina)*

\begin{abstract}
This paper develops a model for demand-system estimations, whose coefficients are own-price Marshallian elasticities and elasticities of substitution between goods. The model satisfies the homogeneity, symmetry and, eventually, adding-up restrictions implied by consumer theory, and is primarily useful for the estimation of the demands of several goods of the same industry or group of products. The characteristics of the model are compared to other existing alternatives (logarithmic, translog, AIDS and QUAIDS demand systems). The model is finally applied to estimate the demands for several carbonated soft drinks in Argentina, and its results are presented, together with the ones obtained with the other estimation methods.
\end{abstract}

\section{Resumen}

Este trabajo desarrolla un modelo para estimaciones de sistemas de demanda, cuyos coeficientes son elasticidades-precio marshalianas directas y elasticidades de sustitución entre bienes. El modelo satisface las restricciones de homogeneidad, simetría y, eventualmente, aditividad surgidas de la teoría del consumidor, y es útil principalmente para estimar demandas de varios bienes de la misma industria o grupo de productos. Las características del modelo se comparan con las de otras alternativas existentes (sistemas logarítmicos, translogarítmicos, AIDS y QUAIDS). Finalmente, el modelo se aplica a la estimación de la demanda de bebidas gaseosas en la Argentina, y se presentan sus resultados, junto con los que se obtienen de aplicar los otros métodos de estimación.

JEL Classification: C30, C51, D12, L66.

Keywords: Demand Systems, Elasticity of Substitution, Simultaneous Equations, Carbonated Soft Drinks.

\section{Introduction}

This paper develops a model for demand-system estimations, based on a logarithmic form. The basic coefficients to estimate, therefore, are demand elasticities. To avoid certain estimation problems, and to incorporate several restrictions implied by consumer theory (namely, homogeneity, symmetry and, eventually, adding-up), the original coefficients of the model are transformed, and the equations end up as linear functions of the own-price Marshallian elasticities of the different goods and the elasticities of substitution between those goods. The model is primarily useful for the estimation of the demands for several goods of the same industry or group of products, rather than for demand estimations of large

\footnotetext{
${ }^{*}$ The views and opinions expressed in this publication are those of the author and are not necessarily those of
} 
consumption categories.

The paper is organized as follows. In section 1 we review the theoretical concept of elasticity of substitution, and its relationships with the Marshallian and Hicksian demand elasticities. In section 2 the model is presented, and in section 3 its main characteristics are compared with the ones of other alternative demand systems. In section 4 the model is applied to a database of supermarket sales of carbonated soft drinks in Argentina, and its results are tested and compared to the ones generated by the alternative demand systems. Finally, in section 5 we summarize the main conclusions of the whole paper.

\section{The concept of elasticity of substitution}

The concept of elasticity of substitution, created by Allen (1938), measures the relative change in the ratio between the quantities of two goods consumed by a certain individual as a response to a relative change in the ratio of the prices of those goods. It is defined for a given level of the individual's utility, i.e., for a situation where that individual is located at a certain indifference curve ${ }^{1}$.

For two arbitrary goods i and j, consumed at quantities $Q_{i}$ and $Q_{j}$ and bought at prices $P_{i}$ and $P_{j}$, the elastiticity of substitution between those goods $\left(\sigma_{i j}\right)$ is defined as:

$$
\sigma_{\mathrm{ij}}=-\frac{\mathrm{d}\left(\mathrm{Q}_{\mathrm{i}} / \mathrm{Q}_{\mathrm{j}}\right) /\left(\mathrm{Q}_{\mathrm{i}} / \mathrm{Q}_{\mathrm{j}}\right)}{\mathrm{d}\left(\mathrm{P}_{\mathrm{i}} / \mathrm{P}_{\mathrm{j}}\right) /\left(\mathrm{P}_{\mathrm{i}} / \mathrm{P}_{\mathrm{j}}\right)}
$$

As one of the basic implications of consumer theory, which holds for differentiable utility functions, is that price ratios are equated to marginal utility ratios, it is possible to write (1) in the following alternative form:

$$
\sigma_{\mathrm{ij}}=-\frac{\mathrm{d}\left(\mathrm{Q}_{\mathrm{i}} / \mathrm{Q}_{\mathrm{j}}\right) /\left(\mathrm{Q}_{\mathrm{i}} / \mathrm{Q}_{\mathrm{j}}\right)}{\mathrm{d}\left(\mathrm{U}_{\mathrm{i}} / \mathrm{U}_{\mathrm{j}}\right) /\left(\mathrm{U}_{\mathrm{i}} / \mathrm{U}_{\mathrm{j}}\right)}
$$

where $U_{i}$ and $U_{j}$ are the marginal utilities of goods $\mathrm{i}$ and $\mathrm{j}$ evaluated at $Q_{i}$ and $Q_{j}{ }^{2}$ If the corresponding utility function is homogeneous, moreover, this equation can be transformed to reach the following expression:

\footnotetext{
CEMA University.

${ }^{1}$ The concept of elasticity of substitution can also be applied in production theory. In that case it refers to ratios of input quantities and input prices, evaluated at a fixed output level.

${ }^{2}$ In fact, the definitions of $\sigma_{i j}$ under (1) and (2) are identical for a case of two goods. If there are more than two commodities, then the two definitions may differ. For more details about this, see Blackorby and Russell (1989).
} 


$$
\sigma_{i j}=-\frac{U_{i} \cdot U_{j}}{U \cdot U_{i j}}=-\frac{U_{i} \cdot U_{j}}{U \cdot U_{j i}}=\sigma_{j i}
$$

where $U_{i j}=U_{j i}$ is the symmetric second derivative of the utility function with respect to $Q_{i}$ and $Q_{j}$. As we can see in (3), the elasticity of substitution is a symmetric concept, which is the same whether we are measuring the substitution of good $\mathrm{i}$ for good $\mathrm{j}$ or the substitution of good j for good $\mathrm{i}$.

The elasticity of substitution between goods $i$ and $j$ can also be related to the cross elasticities of demand for those goods. Let us consider, for example, the Hicksian demand elasticity of good $\mathrm{i}$ with respect to $\operatorname{good} \mathrm{j}\left(\varepsilon_{i j}\right)$, which is defined for a given level of utility. It can be shown that:

$\varepsilon_{i j}=\frac{\partial Q_{i}}{\partial P_{j}} \cdot \frac{P_{j}}{Q_{i}}=\sigma_{i j} \cdot s_{j}$

where $s_{j}$ is the share of good $\mathrm{j}$ in consumer's total expenditure. But as the Hicksian demand elasticity and the ordinary, or Marshallian, demand elasticity $\left(\eta_{i j}\right)$ are related in the following way by the so-called "Slutsky equation":

$\eta_{\mathrm{ij}}=\varepsilon_{\mathrm{ij}}-\eta_{\mathrm{iY}} \cdot \mathrm{s}_{\mathrm{j}}$

where $\eta_{i Y}$ is the income elasticity of good i, then we can combine (4) and (5) to obtain the following alternative expression:

$\eta_{\mathrm{ij}}=\mathrm{s}_{\mathrm{j}} \cdot\left(\sigma_{\mathrm{ij}}-\eta_{\mathrm{iY}}\right)$

which is expressed in terms of an income elasticity and a symmetric substitution elasticity ${ }^{3}$. As we will see, this formula will be useful to estimate a particular class of demand systems, where elasticities of substitution will be related among themselves.

\section{The substitution elasticity demand system}

Let us define a system of $\mathrm{N}$ demands, each of which has the following form:

$$
\ln \left(\mathrm{Q}_{\mathrm{i}}\right)=\alpha_{\mathrm{i}}+\eta_{\mathrm{ii}} \cdot \ln \left(\mathrm{P}_{\mathrm{i}}\right)+\sum_{\mathrm{j} \neq \mathrm{i}} \eta_{\mathrm{ij}} \cdot \ln \left(\mathrm{P}_{\mathrm{j}}\right)+\eta_{\mathrm{iY}} \cdot \ln (\mathrm{Y})
$$

where $Y$ is consumer's income. Due to the logarithmic nature of the model, its coefficients $\left(\eta_{i i}, \eta_{i j}, \eta_{i Y}\right)$ are Marshallian demand elasticities. 
Let us now substitute (6) into (7). What we obtain is:

$\ln \left(Q_{i}\right)=\alpha_{i}+\eta_{i i} \cdot \ln \left(P_{i}\right)+\sum_{j \neq i} \sigma_{i j} \cdot s_{j} \cdot \ln \left(P_{j}\right)+\eta_{i Y} \cdot\left[\ln (Y)-\sum_{j \neq i} s_{j} \cdot \ln \left(P_{j}\right)\right]$

Let us now recall that Marshallian demands are homogeneous of degree zero in prices and income, and write the corresponding restriction in elasticity form:

$\eta_{\mathrm{iY}}=-\eta_{\mathrm{ii}}-\sum_{\mathrm{j} \neq \mathrm{i}} \eta_{\mathrm{ij}}$

Substituting (6) into (9), this implies:

$\eta_{\mathrm{iY}}=\frac{-\eta_{\mathrm{ii}}-\sum_{\mathrm{j} \neq \mathrm{i}} \mathrm{s}_{\mathrm{j}} \cdot \sigma_{\mathrm{ij}}}{\mathrm{s}_{\mathrm{i}}}$

which, replaced into (8), generates the following demand system:

$\ln \left(Q_{i}\right)=\alpha_{i}+\eta_{i i} \cdot\left[\ln \left(P_{i}\right)-\frac{\ln (Y)-\sum_{j \neq i} s_{j} \cdot \ln \left(P_{j}\right)}{s_{i}}\right]+\sum_{j \neq i} \sigma_{i j} \cdot s_{j} \cdot\left[\ln \left(P_{j}\right)-\frac{\ln (Y)-\sum_{j \neq i} s_{j} \cdot \ln \left(P_{j}\right)}{s_{i}}\right]$

The system of $\mathrm{N}$ equations defined by (11), which we will call "substitution elasticity demand system" (SEDS), is a linear system whose coefficients are the own-price Marshallian demand elasticities and the elasticities of substitution between goods. As those elasticities of substitution are symmetric (that is, $\sigma_{i j}=\sigma_{j i}$ ), this system displays the symmetry property, together with the homogeneity property implied by (9).

The inclusion of the homogeneity and symmetry restrictions in this demand system model reduces the number of elasticity coefficients from $N \cdot(N+1)$ to $N+N \cdot(N-1) / 2$. This is the result of the $N+N \cdot(N-1) / 2$ restrictions imposed to the system.

SEDS is also capable to incorporate the so-called "adding-up restriction" of consumer theory. In order to do that, it is useful to write that restriction in a way that relates Marshallian own-price elasticities and cross-price elasticities. This form is usually called "Cournot aggregation condition", and it implies that:

$\eta_{\mathrm{ii}}=-1-\frac{\sum_{\mathrm{j} \neq \mathrm{i}} \eta_{\mathrm{ji}} \cdot \mathrm{s}_{\mathrm{j}}}{\mathrm{s}_{\mathrm{i}}}$

\footnotetext{
${ }^{3}$ For a more complete explanation of these relationships, see Barten (1993).
} 
Combining (9), (10) and (12), it is possible to obtain that:

$\eta_{\mathrm{ii}}=-1-\sum_{\mathrm{j} \neq \mathrm{i}} \eta_{\mathrm{jj}}-\sum_{\mathrm{k}} \sum_{\mathrm{j} \neq \mathrm{i}} \sigma_{\mathrm{kj}} \cdot \mathrm{s}_{\mathrm{j}}$

and this can be substituted into (11). With this substitution we can eliminate the $\eta_{i i}$ coefficient in one of the $\mathrm{N}$ equations of the $\operatorname{model}^{4}$, and we therefore have a system with $N-1$ own-price elasticity coefficients and $N \cdot(N-1) / 2$ elasticities of substitution.

\section{Characteristics of SEDS}

The main characteristics of the proposed model are inherited from the fact that it is originated in a logarithmic demand system and from the restrictions imposed to it. Probably the most noticeable one is that its main coefficients are direct estimates of different elasticity concepts (namely, own-price and substitution elasticities). This allows for a straightforward interpretation of its results, which is something that does not occur when we use other more indirect models.

Another characteristic of SEDS is that its equations do not come from the maximization of an explicit utility function subject to a budget constraint, but they rather are a local approximation of the results generated by an arbitrary function. This approximation is nevertheless meaningful, since the signs and magnitudes of the estimated coefficients can be tested for consistency with different postulated utility functions ${ }^{5}$. Due to the restrictions imposed, we know that those estimates will also be consistent with some general properties of consumer demand functions, namely homogeneity of degree zero, symmetry of the Slutsky matrix and, if included, the adding-up restriction.

Compared to a more general logarithmic demand system, the main advantage of SEDS is that it can incorporate the symmetry restriction in a very natural way. As cross-price elasticities are generally not symmetric, one of the main problems of logarithmic demand systems is that they typically violate symmetry. They also generally violate the adding-up property, unless that constraint is imposed through a set of Cournot aggregation conditions that apply to each of the equations to be estimated. Homogeneity restrictions, conversely, are

\footnotetext{
${ }^{4}$ Note that (13) cannot be substituted into the $\mathrm{N}$ equations separately, since it is in fact a single constraint and not a set of $\mathrm{N}$ independent restrictions.

${ }^{5}$ It is possible to check, for example, if estimates are consistent with the demands generated by a Cobb-Douglas utility function, that display own-price elasticities equal to -1 and elasticities of substitution equal to 1 . Other utility functions with constant elasticities of substitution (for example, the ones that constitute the CES family) do not generate demand functions with constant own-price elasticities, but they can nevertheless be tested using the average elasticity values implied for the data set under analysis.
} 
easily imposed on logarithmic demands, and they are also easily included in the SEDS model.

Compared to other more sophisticated demand systems based on the so-called "flexible functional forms", SEDS has the advantage that it is more efficient in the use of information. Consider, for example, three common specifications such as the translog demand system, originated in the work of Christensen, Jorgenson and Lau (1975), the "almost ideal demand system" (AIDS), proposed by Deaton and Muellbauer (1980), and the "quadratic almost ideal demand system" (QUAIDS), created by Banks, Blundell and Lewbel (1997). They can all be thought of as part of the same family of demand systems, built upon a series of equations whose dependent variables are expenditure shares. For the case of the translog demand system, those equations have the following form:

$\mathrm{s}_{\mathrm{i}}=\alpha_{\mathrm{i}}+\beta_{\mathrm{ii}} \cdot \ln \left(\mathrm{P}_{\mathrm{i}}\right)+\sum_{\mathrm{j} \neq \mathrm{i}} \beta_{\mathrm{ij}} \cdot \ln \left(\mathrm{P}_{\mathrm{j}}\right)$

while, for the case of AIDS, they have the following form:

$\mathrm{s}_{\mathrm{i}}=\alpha_{\mathrm{i}}+\beta_{\mathrm{ii}} \cdot \ln \left(\mathrm{P}_{\mathrm{i}}\right)+\sum_{\mathrm{j} \neq \mathrm{i}} \beta_{\mathrm{ij}} \cdot \ln \left(\mathrm{P}_{\mathrm{j}}\right)+\beta_{\mathrm{iY}} \cdot \ln \left(\frac{\mathrm{Y}}{\mathrm{PI}_{1}}\right)$

where $P I_{l}$ is an arithmetic price index, and, for the case of QUAIDS, they have the following form:

$\mathrm{s}_{\mathrm{i}}=\alpha_{\mathrm{i}}+\beta_{\mathrm{ii}} \cdot \ln \left(\mathrm{P}_{\mathrm{i}}\right)+\sum_{\mathrm{j} \neq \mathrm{i}} \beta_{\mathrm{ij}} \cdot \ln \left(\mathrm{P}_{\mathrm{j}}\right)+\beta_{\mathrm{iY}} \cdot \ln \left(\frac{\mathrm{Y}}{\mathrm{PI}_{1}}\right)+\frac{\lambda_{\mathrm{iY}}}{\mathrm{PI}_{2}} \cdot \ln \left(\frac{\mathrm{Y}}{\mathrm{PI}_{1}}\right)^{2}$

where $P I_{2}$ is a geometric price index.

To fulfill the homogeneity, symmetry and adding-up properties of demand functions derived from consumer theory, these systems have to be estimated imposing certain restrictions on the coefficients, which are basically the following:

$\sum_{\mathrm{i}} \alpha_{\mathrm{i}}=1 ; \quad \sum_{\mathrm{i}} \beta_{\mathrm{ij}}=0 ; \quad \sum_{\mathrm{j}} \beta_{\mathrm{ij}}=0 ; \quad \beta_{\mathrm{ij}}=\beta_{\mathrm{ji}} ; \quad \sum_{\mathrm{i}} \beta_{\mathrm{iY}}=0 ; \quad \sum_{\mathrm{i}} \lambda_{\mathrm{iY}}=0$

The imposition of those conditions, however, reduces the number of coefficients in such a way that makes one of the $\mathrm{N}$ equations redundant. Therefore, we end up with systems of $\mathrm{N}-1$ equations, each of which has the expenditure shares of $\mathrm{N}-1$ goods as their dependent variables.

In comparison with these systems whose estimation is performed using expenditure share equations, SEDS has the advantage of being more efficient. This is because it does not 
'lose one equation", and because it keeps the information about total quantities, instead of transforming those quantities into expenditure shares. The parameters estimated are also easier to interpret, since they are direct estimates of own-price and substitution elasticities, instead of coefficients that have to be transformed in order to be interpreted as elasticities.

The main disadvantage of SEDS with respect to the other demand systems mentioned in this section, however, is that their dependent variables are not exogenous. This is because those variables are not prices and income but transformations of those variables, which also include expenditure shares in their formulae. But as expenditure shares are based on prices and quantities, and quantities are supposed to be the consumers' decision variables, then all the variables built using expenditure share information are, at least partly, endogenous to the model. In order to obtain consistent estimations of the coefficients, therefore, it is necessary to use instrumental variables. The choice of those instrumental variables, however, is more or less obvious, since we are basing our analysis in the behavior of consumers who take prices and income as given. Using prices and income as instrumental variables, and estimating the system of equations through a method that incorporates those instrumental variables (such as two-stage least squares, or three-stage least squares), we are able to obtain a set of consistent and unbiased estimators for the elasticity coefficients embedded in the model ${ }^{6}$.

SEDS also provides a natural way to simplify the estimation when we are working with a set of goods that we have some additional information about. Let us imagine, for example, that we can pool the goods into different groups and classes (based on objective characteristics of those goods). We can assume, for example, that two goods that belong to the same class may have the same elasticity of substitution with respect to another good that belongs to a different class, and that hypothesis can be easily incorporated into the estimation of SEDS. In other models, those simplifications are much more difficult to handle, since they imply redefining the independent variables of the regression ${ }^{7}$.

Being a model that does not come from the maximization of an explicit utility function, we think that SEDS is more suitable for demand systems that include several related goods (for example, goods from the same industry) but not large consumption categories. This is the case, for example, of estimations based on supermarket scanned data for products

\footnotetext{
${ }^{6}$ In fact, the assumption that prices and income are exogenous variables while quantities are endogenous is determined by the idea that we work using individuals' level data. If we are working with aggregate data, however, prices are exogenous if supplies are perfectly elastic and demands adjust to clear the market. For a deeper analysis of this assumption and alternative ones, see Moschini and Vissa (1993).

${ }^{7}$ There is a version of the AIDS model, called PCAIDS, which essentially makes an assumption like that. In order to incorporate that assumption to an econometric model, however, it is necessary to multiply and divide the coefficients by the expenditure shares of the goods under analysis, and this implies a change in the specification
} 
that belong to the same industry, in which we can make the assumption that their demands are related among themselves but basically independent from the demands of other goods ${ }^{8}$.

In a context like that, the imposition of homogeneity and symmetry restrictions is very important, but adding-up may be less important or even inconvenient. This is because demands are supposed to be functions of income and all the available prices, and substitution patterns between goods are supposed to be symmetric. However, there is no need to assume that, when income changes, the ratio between expenditure (in those goods) and income will remain the same. Imposing an adding-up restriction is equivalent to assume that the average income elasticity of the estimated goods is equal to one, and this may not be reasonable if we are dealing with a group of goods from an industry that represents a relatively small fraction of total consumers' income.

\section{Application to the Argentine carbonated soft-drink industry}

In this section we will apply SEDS to a data set of 93 weekly observations from the Argentine carbonated soft-drink industry, during the years 2004 and 2005. That data set is proprietary. It was built by a firm that specializes in market research, using scanned data from the main supermarket chains that operate in Argentina. To avoid possible confidentiality problems, we have pooled the data into eight commodity categories. Each of them represents a particular taste and variety of carbonated soft drinks, but it includes information from several different brands and companies. The categories defined in that way are normal cola (good 1), light cola (good 2), normal lime soda (good 3), light lime soda (good 4), normal orange soda (good 5), light orange soda (good 6), normal grapefruit soda (good 7) and tonic water (good 8).

For each of the goods in our database we have price and quantity data. Quantity is measured in liters sold in each week, while price is measured in Argentine pesos per liter, and is obtained from dividing total sales of the corresponding good by total quantity of that good. We also have two additional variables to be included as demand shifters in all the equations. One of them is the consumers' nominal income, estimated by multiplying the Argentine Monthly Estimator of Economic Activity (EMAE) and the Argentine Consumer Price Index

\footnotetext{
of the model itself. For more details about PCAIDS, see Epstein and Rubinfeld (2002).

${ }^{8}$ The use of SEDS to estimate the demands for several goods of the same industry also makes convenient to define expenditure shares as the ratio between the expenditure on each good and the total expenditure in the group of goods whose demands are estimated. Using a measure of expenditure shares that relates expenditure on each good to total consumers' expenditure in every good of the economy, conversely, may generate a problem of measurement of the elasticities of substitution, first pointed out by Frisch (1959).
} 
$(\mathrm{CPI})^{9}$. As those indices are published monthly, we had to interpolate them to obtain weekly series. The other demand shifter is the average daily maximum temperature in the Buenos Aires area for each of the weeks of the data set, measured in Celsius degrees ${ }^{10}$. This is supposed to be an important determinant of soft-drinks consumption.

Other variables used in our regressions come from transforming the original variables. The expenditure shares, for example, are the ratios between the product of price times quantity divided by total expenditure in carbonated soft drinks. The average price indices required for the estimation of the AIDS and QUAIDS models, similarly, are arithmetic and geometric means of the eight products' prices, which use average expenditure shares as weighting factors.

The main information about the data set used is summarized in table 1 . In it we see that the average carbonated soft drink prices vary considerably according to the different tastes and varieties, and have followed an increasing path during the period 2004-2005 in Argentina. On average, they have grown $20 \%$ between the second quarter of 2004 and the fourth quarter of 2005 , which is a period where the CPI increased $14 \%$. We can also see that some tastes and varieties have always been more expensive than others, but the evolution of prices was not homogeneous. For example, the light sodas are always more expensive on average than the normal sodas with the same taste. However, the light lime soda was cheaper than the tonic water in the first two quarters of 2004, but it became more expensive in the last quarter of 2004 and during the year 2005.

Table 1 also contains information about market shares, calculated as the expenditure share of each good in the total sales of the database. That information shows us that the normal cola is by far the most important carbonated soft drink, with a share that oscillates between $44 \%$ and $46 \%$, followed by the light cola and the normal lime soda, with market shares around $15 \%$. The next most important carbonated soft drink is the normal orange soda, with a share between $8 \%$ and $9 \%$, followed by the light lime soda (7\%) and the grapefruit soda $(5 \%)$. Finally, the light orange soda and the tonic water are the two categories with the smallest consumption (around $2 \%$ each).

\footnotetext{
${ }^{9}$ The source for these two indices is the Argentine National Institute of Statistics and the Census (INDEC).

${ }^{10}$ The source for this information is the Argentine National Meteorological Office.
} 


\section{DESCRIPTION OF THE DATA}

\begin{tabular}{|c|c|c|c|c|c|c|c|c|}
\hline $\begin{array}{l}\text { Concept } \\
\text { Prices (Arg\$/lt) }\end{array}$ & Mar-Jun/04 & Jul-Sep/04 & Oct-Dec/04 & Jan-Mar/05 & Apr-Jun/05 & Jul-Sep/05 & Oct-Dec/05 & Mar04-Dec0 \\
\hline Normal Cola (P1) & 1,2226 & 1,2499 & 1,2762 & 1,3354 & 1,3701 & 1,4059 & 1,4591 & 1,3239 \\
\hline Light Cola (P2) & 1,4033 & 1,4568 & 1,4881 & 1,5620 & 1,6024 & 1,6336 & 1,6641 & 1,5357 \\
\hline Normal Lime (P3) & 1,2039 & 1,2402 & 1,2760 & 1,3276 & 1,3530 & 1,3824 & 1,4277 & 1,3086 \\
\hline Light Lime (P4) & 1,3899 & 1,4261 & 1,4793 & 1,5619 & 1,5986 & 1,6263 & 1,6532 & 1,5249 \\
\hline Normal Orange (P5) & 1,0026 & 1,0189 & 1,0604 & 1,1194 & 1,1446 & 1,1935 & 1,2801 & 1,1086 \\
\hline Light Orange (P6) & 1,5436 & 1,5811 & 1,6634 & 1,7201 & 1,7456 & 1,8112 & 1,8630 & 1,6937 \\
\hline Grapefruit (P7) & 0,7692 & 0,7895 & 0,8341 & 0,9191 & 0,9574 & 1,0188 & 1,0568 & 0,8973 \\
\hline Tonic Water (P8) & 1,4162 & 1,4460 & 1,4589 & 1,5331 & 1,5565 & 1,5522 & 1,6031 & 1,5034 \\
\hline Average Price & 1,2273 & 1,2596 & 1,2929 & 1,3565 & 1,3898 & 1,4256 & 1,4742 & 1,3387 \\
\hline \multicolumn{9}{|l|}{ Expenditure Shares (\%) } \\
\hline Normal Cola (S1) & 44,41 & 45,12 & 44,86 & 44,63 & 45,74 & 46,13 & 44,77 & 45,07 \\
\hline Light Cola (S2) & 15,60 & 16,67 & 15,43 & 14,75 & 15,91 & 15,85 & 15,73 & 15,70 \\
\hline Normal Lime (S3) & 14,70 & 14,30 & 15,22 & 15,67 & 14,76 & 15,08 & 15,96 & 15,06 \\
\hline Light Lime (S4) & 7,15 & 6,70 & 7,03 & 6,94 & 6,62 & 6,22 & 6,55 & 6,76 \\
\hline Normal Orange (S5) & 8,46 & 8,82 & 8,57 & 8,56 & 8,14 & 8,28 & 8,02 & 8,42 \\
\hline Light Orange (S6) & 1,75 & 1,58 & 1,79 & 1,88 & 2,03 & 2,05 & 2,00 & 1,86 \\
\hline Grapefruit (S7) & 5,95 & 5,07 & 5,23 & 5,46 & 4,98 & 4,71 & 5,07 & 5,24 \\
\hline Tonic Water (S8) & 2,00 & 1,75 & 1,88 & 2,12 & 1,83 & 1,68 & 1,90 & 1,88 \\
\hline \multicolumn{9}{|l|}{ Other variables } \\
\hline Quantity (thous It) & 2442,8 & 2431,7 & 2837,2 & 3094,9 & 2379,4 & 2461,4 & 2826,9 & 2626,7 \\
\hline Expenditure (thous \$) & 2920,4 & 2999,2 & 3594,9 & 4107,0 & 3258,1 & 3465,2 & 4122,4 & 3457,1 \\
\hline Argentine CPI & 147,53 & 148,08 & 150,98 & 154,85 & 159,20 & 162,48 & 167,95 & 155,25 \\
\hline Real Income (EMAE) & 119,36 & 120,25 & 123,35 & 116,51 & 132,52 & 131,26 & 134,30 & 124,91 \\
\hline Temperature $\left({ }^{\circ} \mathrm{C}\right)$ & 21,03 & 17,01 & 24,87 & 28,41 & 19,51 & 16,96 & 24,12 & 21,62 \\
\hline
\end{tabular}


Although relatively stable, these market shares exhibit some changes in the period under analysis. For example, the light cola had, on average, a largest market share than the normal lime soda, but that situation was the opposite in the first and fourth quarters of the year 2005. Similarly, the tonic water had a larger market share than the light orange soda until the first quarter of the year 2005, and a smaller one in the last three quarters ${ }^{11}$.

The last rows of table 1 show some additional information that was used in the regression of the demand equations for the eight products under analysis. We can see, for example, that the total quantity sold by the supermarket chains increased almost $16 \%$ between the second quarter of 2004 and the last quarter of 2005, while the economic activity of Argentina, measured by the EMAE, grew $12.5 \%$. We can also see that the combination of the increases in price and quantity experienced by the carbonated soft drinks of our database generated an increase in total expenditure of $41 \%$ during the period under analysis.

On table 2 we report the main results of the estimation of a demand system that follows the SEDS model developed in section 2 and summarized by equation (11). To perform that estimation we used the prices and market shares of the eight goods of our database, together with our estimation of the nominal income variable (EMAE times CPI), and the natural logarithm of temperature as an additional demand shifter. We also included an autocorrelation correction in the form of an AR(1) process, which reduced the number of available observations to 92 . To estimate the equations we used iterative three-stage least squares (3SLS), that achieved convergence after 63 iterations. The instrumental variables used were the logarithms of the eight prices, together with the logarithm of the nominal income and the logarithm of temperature.

\footnotetext{
${ }^{11}$ This last phenomenon may be due to the fact that the light orange soda is a relatively new product, while the tonic water is much more traditional in Argentina.
} 
2. SEDS ESTIMATION RESULTS

\begin{tabular}{|c|c|c|c|c|}
\hline $\begin{array}{l}\text { Concept } \\
\text { Own-price elasticities }\end{array}$ & Coefficient & Std Error & t-Statistic & Probability \\
\hline Normal Cola $\left(\eta_{11}\right)$ & $-0,909439$ & 0,009135 & $-99,5556$ & 0,0000 \\
\hline Light Cola $\left(\eta_{22}\right)$ & $-0,962948$ & 0,008872 & $-108,5347$ & 0,0000 \\
\hline Normal Lime $\left(\eta_{33}\right)$ & $-0,966867$ & 0,008821 & $-109,6146$ & 0,0000 \\
\hline Light Lime $\left(\eta_{44}\right)$ & $-0,968006$ & 0,009406 & $-102,9092$ & 0,0000 \\
\hline Normal Orange $\left(\eta_{55}\right)$ & $-0,980961$ & 0,008908 & $-110,1195$ & 0,0000 \\
\hline Light Orange $\left(\eta_{66}\right)$ & $-1,020937$ & 0,009477 & $-107,7289$ & 0,0000 \\
\hline Grapefruit $\left(\eta_{77}\right)$ & $-1,019351$ & 0,009358 & $-108,9302$ & 0,0000 \\
\hline Tonic Water $\left(\eta_{88}\right)$ & $-0,990164$ & 0,009462 & $-104,6451$ & 0,0000 \\
\hline Substitution elasticities & & & & \\
\hline NCola/LCola $\left(\sigma_{12}\right)$ & 0,991992 & 0,008968 & 110,6169 & 0,0000 \\
\hline NCola/NLime $\left(\sigma_{13}\right)$ & 0,999899 & 0,008916 & 112,1444 & 0,0000 \\
\hline NCola/LLime $\left(\sigma_{14}\right)$ & 0,986120 & 0,009657 & 102,1163 & 0,0000 \\
\hline NCola/NOrange $\left(\sigma_{15}\right)$ & 0,997926 & 0,008931 & 111,7387 & 0,0000 \\
\hline NCola/LOrange $\left(\sigma_{16}\right)$ & 1,023027 & 0,009470 & 108,0289 & 0,0000 \\
\hline NCola/Grapefruit $\left(\sigma_{17}\right)$ & 1,028563 & 0,009309 & 110,4861 & 0,0000 \\
\hline NCola/Tonic $\left(\sigma_{18}\right)$ & 0,995468 & 0,009591 & 103,7905 & 0,0000 \\
\hline LCola/NLime $\left(\sigma_{23}\right)$ & 0,994056 & 0,008873 & 112,0360 & 0,0000 \\
\hline LCola/LLime $\left(\sigma_{24}\right)$ & 0,960914 & 0,009933 & 96,7434 & 0,0000 \\
\hline LCola/NOrange $\left(\sigma_{25}\right)$ & 0,996308 & 0,009184 & 108,4877 & 0,0000 \\
\hline LCola/LOrange $\left(\sigma_{26}\right)$ & 1,027610 & 0,009532 & 107,8012 & 0,0000 \\
\hline LCola/Grapefruit $\left(\sigma_{27}\right)$ & 1,033140 & 0,009469 & 109,1124 & 0,0000 \\
\hline LCola/Tonic $\left(\sigma_{28}\right)$ & 0,984835 & 0,009698 & 101,5548 & 0,0000 \\
\hline NLime/LLime $\left(\sigma_{34}\right)$ & 0,976619 & 0,009314 & 104,8506 & 0,0000 \\
\hline NLime/NOrange $\left(\sigma_{35}\right)$ & 0,993379 & 0,008670 & 114,5760 & 0,0000 \\
\hline NLime/LOrange $\left(\sigma_{36}\right)$ & 1,028145 & 0,009601 & 107,0886 & 0,0000 \\
\hline NLime/Grapefruit $\left(\sigma_{37}\right)$ & 1,029724 & 0,009514 & 108,2297 & 0,0000 \\
\hline NLime/Tonic $\left(\sigma_{38}\right)$ & 0,989109 & 0,009453 & 104,6335 & 0,0000 \\
\hline LLime/NOrange $\left(\sigma_{45}\right)$ & 0,969757 & 0,009686 & 100,1168 & 0,0000 \\
\hline LLime/LOrange $\left(\sigma_{46}\right)$ & 1,031909 & 0,009940 & 103,8174 & 0,0000 \\
\hline LLime/Grapefruit $\left(\sigma_{47}\right)$ & 1,044679 & 0,010547 & 99,0533 & 0,0000 \\
\hline LLime/Tonic $\left(\sigma_{48}\right)$ & 0,967586 & 0,011008 & 87,8977 & 0,0000 \\
\hline NOrange/LOrange $\left(\sigma_{56}\right)$ & 1,028955 & 0,009497 & 108,3491 & 0,0000 \\
\hline NOrange/Grapefruit $\left(\sigma_{57}\right)$ & 1,037393 & 0,009662 & 107,3717 & 0,0000 \\
\hline NOrange/Tonic $\left(\sigma_{58}\right)$ & 0,995121 & 0,009601 & 103,6458 & 0,0000 \\
\hline LOrange/Grapefruit $\left(\sigma_{67}\right)$ & 1,005344 & 0,009349 & 107,5403 & 0,0000 \\
\hline LOrange/Tonic $\left(\sigma_{68}\right)$ & 1,035423 & 0,010210 & 101,4141 & 0,0000 \\
\hline $\begin{array}{l}\text { Grapefruit/Tonic }\left(\sigma_{78}\right) \\
\text { AR(1) coefficients }\end{array}$ & 1,045786 & 0,010148 & 103,0527 & 0,0000 \\
\hline Eqn 1 (Normal Cola) & 0,669794 & 0,028868 & 23,2021 & 0,0000 \\
\hline Eqn 2 (Light Cola) & 0,669872 & 0,028932 & 23,1534 & 0,0000 \\
\hline Eqn 3 (Normal Lime) & 0,668846 & 0,029005 & 23,0596 & 0,0000 \\
\hline Eqn 4 (Light Lime) & 0,649510 & 0,030666 & 21,1799 & 0,0000 \\
\hline Eqn 5 (Normal Orange) & 0,665150 & 0,029218 & 22,7653 & 0,0000 \\
\hline Eqn 6 (Light Orange) & 0,695093 & 0,028076 & 24,7575 & 0,0000 \\
\hline Eqn 7 (Grapefruit) & 0,679118 & 0,028625 & 23,7246 & 0,0000 \\
\hline Eqn 8 (Tonic Water) & 0,630016 & 0,034030 & 18,5138 & 0,0000 \\
\hline
\end{tabular}


As we see, the results obtained are very reasonable and precise. All the own-price elasticities have the right signs and are significantly different from zero at any possible probability level, with values that range from -0.90 to $-1.02 .^{12}$ The substitution elasticities also have the expected signs and they are also significantly different from zero at any possible probability level, with values that range from 0.96 to 1.05 . We also see that the estimation residuals seem to have an important autocorrelation (something that is expected, due to the weekly frequency of the series), which averages 0.67 .

With the results reported on table 2, we have calculated all the implicit income and cross-price elasticities of the model, following equations (10) and (6). They are the ones that appear on table 3. All the income elasticities have the expected positive sign, with values that range from 0.76 to 0.81 . Six of them are statistically different from zero at a $1 \%$ level of significance, but the remaining two are not statistically different from zero at a $10 \%$ level of significance $^{13}$. They correspond to the demand equations for light orange soda and tonic water, which are the two products with the smallest expenditure shares.

The Marshallian cross-price elasticities implied by our SEDS estimation, correspondingly, have also the expected positive sign, with values that range from 0.10 to 0.0036. Twenty-one of them are statistically different from zero at a $1 \%$ level of significance, six of them are statistically different from zero at a $10 \%$ level of significance, and the remaining twenty-nine are not statistically different from zero at a $10 \%$ level of significance. In particular, we can see that the cross elasticities that correspond to the demands of the goods with the smallest market shares (light lime, normal orange, light orange, grapefruit and tonic water) tend not to be significantly different from zero.

\footnotetext{
12 These results imply relatively small price elasticities, in comparison with other studies of the carbonated soft drink industry. For example, using an AIDS specification, Dahr and others (2005) find own-price elasticities for these products that vary from -2 to -4 . These elasticities, however, correspond to the US market and were calculated for particular brands and not for different product categories.

${ }^{13}$ To estimate if these elasticities were statistically different from zero, we first calculated their implicit standard deviations, using the standard deviations of the parameters estimated by the model. We then calculated their corresponding t-statistics, and obtained the p-values for a situation with 676 degrees of freedom (that is, 92 observations times 8 equations minus 60 coefficients).
} 
3. MARSHALLIAN ELASTICITIES IMPLIED BY THE SEDS ESTIMATION

\begin{tabular}{|c|c|c|c|c|c|c|c|c|c|}
\hline Equation/Variable & P1 & P2 & P3 & P4 & P5 & P6 & P7 & P8 & YN \\
\hline Normal Cola (Q1) & $-0,909439$ & 0,030100 & 0,030067 & 0,012570 & 0,016633 & 0,004140 & 0,011971 & 0,003676 & 0,800281 \\
\hline P-value & $(0,0000)$ & $(0,0000)$ & $(0,0000)$ & $(0,0000)$ & $(0,0000)$ & $(0,0000)$ & $(0,0000)$ & $(0,0000)$ & $(0,0000)$ \\
\hline Light Cola (Q2) & 0,086983 & $-0,962948$ & 0,029380 & 0,010952 & 0,016605 & 0,004249 & 0,012278 & 0,003500 & 0,799001 \\
\hline P-value & $(0,0026)$ & $(0,0000)$ & $(0,0023)$ & $(0,0115)$ & $(0,0021)$ & $(0,0004)$ & $(0,0003)$ & $(0,0037)$ & $(0,0000)$ \\
\hline Normal Lime (Q3) & 0,095384 & 0,032310 & $-0,966867$ & 0,012740 & 0,017262 & 0,004458 & 0,012661 & 0,003783 & 0,788268 \\
\hline P-value & $(0,0014)$ & $(0,0019)$ & $(0,0000)$ & $(0,0045)$ & $(0,0020)$ & $(0,0003)$ & $(0,0003)$ & $(0,0025)$ & $(0,0000)$ \\
\hline Light Lime (Q4) & 0,099423 & 0,030677 & 0,031796 & $-0,968006$ & 0,017187 & 0,004951 & 0,014638 & 0,003806 & 0,765528 \\
\hline P-value & $(0,1614)$ & $(0,2148)$ & $(0,1802)$ & $(0,0000)$ & $(0,1948)$ & $(0,0910)$ & $(0,0766)$ & $(0,1998)$ & $(0,0000)$ \\
\hline Normal Orange (Q5) & 0,089514 & 0,030928 & 0,029230 & 0,011528 & $-0,980961$ & 0,004268 & 0,012484 & 0,003688 & 0,799321 \\
\hline P-value & $(0,0962)$ & $(0,0990)$ & $(0,1040)$ & $(0,1535)$ & $(0,0000)$ & $(0,0546)$ & $(0,0463)$ & $(0,1011)$ & $(0,0000)$ \\
\hline Light Orange (Q6) & 0,096672 & 0,034396 & 0,033078 & 0,015109 & 0,018550 & $-1,020937$ & 0,010320 & 0,004273 & 0,808539 \\
\hline P-value & $(0,7087)$ & $(0,7028)$ & $(0,7021)$ & $(0,6972)$ & $(0,7010)$ & $(0,0000)$ & $(0,7318)$ & $(0,6927)$ & $(0,1593)$ \\
\hline Grapefruit (Q7) & 0,101694 & 0,036144 & 0,034160 & 0,016352 & 0,019732 & 0,003762 & $-1,019351$ & 0,004574 & 0,802934 \\
\hline P-value & $(0,2617)$ & $(0,2521)$ & $(0,2592)$ & $(0,2293)$ & $(0,2435)$ & $(0,3139)$ & $(0,0000)$ & $(0,2271)$ & $(0,0001)$ \\
\hline Tonic Water (Q8) & 0,099132 & 0,032863 & 0,032172 & 0,012991 & 0,018481 & 0,004830 & 0,014172 & $-0,990164$ & 0,775522 \\
\hline P-value & $(0,6983)$ & $(0,7122)$ & $(0,7066)$ & $(0,7350)$ & $(0,6987)$ & $(0,6469)$ & $(0,6339)$ & $(0,0000)$ & $(0,1719)$ \\
\hline
\end{tabular}


To check if the estimates generated by the SEDS model were good and reasonable, we compared them with the ones produced by other alternative specifications. One first natural experiment was to compare them with the ones produced by other less restrictive logarithmic forms. These forms were an unconstrained logarithmic system, a logarithmic system to which we imposed $\mathrm{N}$ homogeneity restrictions given by equation (9), and a logarithmic system to which we imposed the same homogeneity restrictions plus $\mathrm{N}$ adding-up restrictions given by equation (12).

The main results of these three alternative specifications appear on the first three columns of table 4. In it we see that the unrestricted logarithmic and homogeneous logarithmic regressions generate very poor estimations of the own-price elasticities of the different carbonated soft drinks, since only one of the eight estimated coefficients is significantly different from zero at a 5\% level of probability (and that is the same coefficient in both cases: the own-price elasticity of the grapefruit soda). We also see that one coefficient, which corresponds to the own-price elasticity of the light lime soda, displays the wrong sign in both estimations ${ }^{14}$.

When we move to the estimates generated by the logarithmic specification that includes both the homogeneity and adding-up restrictions, which appear on the third column of table 4, the results improve, since all the estimated own-price elasticities have the right sign and are statistically different from zero ${ }^{15}$. They also end up being around the same range of values (from -0.99 to -1.24 ), something that did not happen with the unrestricted logarithmic and homogeneous logarithmic regressions. The estimates for the cross-price elasticities, not reported on table 4, are nevertheless disappointing, since only 16 out of 48 coefficients display the expected positive sign, and only 7 of them are statistically different from zero at a $5 \%$ level of significance.

\footnotetext{
${ }^{14}$ Many other coefficients estimated by these models, not reported on table 4, are also not significant and/or display the wrong sign. These two systems were estimated using iterative seemingly unrelated regressions (SUR), since endogeneity is not an issue in those models and therefore it was not necessary to use 3SLS.

${ }^{15}$ This model, unlike the two previous ones, was estimated using iterative 3SLS, since some of its variables are functions of the expenditure shares, which are endogenous to the demand systems.
} 
4. COMPARISON WITH ALTERNATIVE SPECIFICATIONS

\section{Concept}

Own-price elasticities

Normal Cola $\left(\eta_{11}\right)$

P-value

Light Cola $\left(\eta_{22}\right)$

P-value

Normal Lime $\left(\eta_{33}\right)$

P-value

Light Lime $\left(\eta_{44}\right)$

P-value

Normal Orange $\left(\eta_{55}\right)$

P-value

Light Orange $\left(\eta_{66}\right)$

P-value

Grapefruit $\left(\eta_{77}\right)$

P-value

Tonic Water $\left(\eta_{88}\right)$

P-value

R2 coefficients

Eqn 1 (Normal Cola)

Eqn 2 (Light Cola)

Eqn 3 (Normal Lime)

Eqn 4 (Light Lime)

Eqn 5 (Normal Orange)

Eqn 6 (Light Orange)

Eqn 7 (Grapefruit)

Eqn 8 (Tonic Water)

System
Logarithmic Log homog Log hom add

$\begin{array}{rr}-2,823139 & -2,572226 \\ (0,0778) & (0,0836) \\ -0,857560 & -0,928162 \\ (0,5128) & (0,4625) \\ -1,720827 & -1,840428 \\ (0,0929) & (0,0680) \\ 0,744404 & 0,284129 \\ (0,5442) & (0,8125) \\ -0,145256 & -0,256624 \\ (0,8911) & (0,7972) \\ -1,139967 & -0,691388 \\ (0,2161) & (0,4495) \\ -1,270181 & -1,485302 \\ (0,0000) & (0,0000) \\ -0,784639 & -0,849099 \\ (0,2620) & (0,1576) \\ & \\ 0,635014 & 0,637645 \\ 0,634433 & 0,634744 \\ 0,764246 & 0,765495 \\ 0,779942 & 0,778974 \\ 0,633909 & 0,636285 \\ 0,802762 & 0,793504 \\ 0,818226 & 0,817529 \\ 0,822214 & 0,818397 \\ 0,754733 & 0,753355\end{array}$

$-1,035558$

$(0,0000)$

$-1,017593$

$(0,0000)$

$-1,005025$

$(0,0000)$

$-1,008758$

$(0,0000)$

$-1,000430$

$(0,0000)$

$-1,020176$

$(0,0000)$

$-1,016708$

$(0,0000)$

$-1,320462$

$(0,0000)$

0,609927

0,240562

0,737549

0,571270

0,683496

0,728861

0,771870

0,753542

0,682988

\section{SEDS SEDS add Translog}

$-0,909439$

$(0,0000)$

$-0,962948$

$(0,0000)$

$-0,966867$

$(0,0000)$

$-0,968006$

$(0,0000)$

$-0,980961$

$(0,0000)$

$-1,020937$

$(0,0000)$

$-1,019351$

$(0,0000)$

$-0,990164$

$(0,0000)$

0,663196

0,337887

0,751490

0,617983

0,712922

0,739155

0,798314

0,745752

0,708036
$-1,093820$

$(0,0000)$

$-1,104997$

$(0,0000)$

$-1,100530$

$(0,0000)$

$-1,162378$

$(0,0000)$

$-1,116746$

$(0,0000)$

$-1,101806$

$(0,0000)$

$-1,095422$

$(0,0000)$

$-1,153218$

$(0,0000)$

0,638195

0,349423

0,753588

0,616290

0,715158

0,738262

0,794140

0,058421

0,577047
$-2,179922$

(0,0000)

$-0,304239$

$(0,4786)$

$-2,284558$

$(0,0000)$

$-1,644479$

$(0,0000)$

$-2,049495$

$(0,0000)$

0,291981

$(0,5173)$

$-1,354494$

$(0,0000)$

$-1,249426$

$(0,0000)$

0,345966

0,572715

0,858812

0,552046

0,587199

0,761832

0,809960

0,705491
0,528353
AIDS

$(0,0000)$

$-0,327633$

$(0,3775)$

$-2,293674$

$(0,0000)$

$-1,601901$

$(0,0000)$

$-2,091321$

$(0,0000)$

0,272988

$(0,5456)$

$-1,340096$

$(0,0000)$

$-1,200157$

$(0,0000)$

0,474873

0,737956

0,861034

0,674068

0,739842

0,799405

0,817845

0,720770

0,639256
QUAIDS

$-2,051935$

$(0,0000)$

$-0,101534$

$(0,7850)$

$-2,281830$

$(0,0000)$

$-1,619775$

$(0,0000)$

$-1,939368$

$(0,0000)$

0,690143

$(0,0963)$

$-1,374956$

$(0,0000)$

$-1,025378$

$(0,0000)$

0,510483

0,755153

0,861627

0,680257

0,740217

0,844380

0,820095

0,724060

0,660205 
All logarithmic models produce relatively high $\mathrm{R}^{2}$ coefficients in most equations. As we expect, these coefficients are generally higher in the unrestricted model, and a bit lower in the homogeneous one. In the homogeneous model with adding-up restrictions they are even lower, and this is particularly noticeable for the case of the equations that represent the demand functions of light cola and light lime soda. Compared to the $\mathrm{R}^{2}$ coefficients generated by the SEDS regressions, moreover, they are lower in seven out of eight equations. This is particularly noticeable since the homogeneous model with adding-up restrictions is a model with 80 coefficients, while SEDS is a model with only 60 coefficients.

To compare the goodness of fit of the different models we have also estimated the systems' $\mathrm{R}^{2}$ coefficients, based on the methodology proposed by McElroy (1977). Comparing those coefficients among themselves we can conclude that the SEDS model performs only slightly worse than the unrestricted and homogeneous logarithmic models (that are models with 96 and 88 coefficients, respectively), but better than the homogeneous logarithmic model with adding-up restrictions.

The next alternative specification whose results are reported on table 4 is a variety of the SEDS model that includes one adding-up restriction given by equation (13). Its results, obtained after performing iterative 3SLS regressions, are relatively similar to the ones generated by the SEDS model without the adding-up restriction, with the particularity that the estimated own-price elasticities are higher. The estimated substitution elasticities, not reported on table 4, are also higher in general, and they all display the right positive sign and are statistically different from zero at any reasonable level of significance. The only weakness of this model seems to be its goodness of fit, since the estimated $R^{2}$ coefficient of the system is considerably lower than the one produced by the SEDS model without the adding-up restriction. This may be due to the fact that imposing that restriction is equivalent to force the average income elasticity of the eight goods to be equal to one. This may generate a relatively high distortion, considering that our previous estimates for those income elasticities were on the range between 0.76 to 0.81 .

The last three columns of table 4 show the results produced by the three flexible functional forms that run expenditure share regressions to estimate the demand parameters (i.e., translog, AIDS and QUAIDS). They were all made using iterative SUR equations, and measuring income using the variable of total expenditure in carbonated soft drinks, instead of the EMAE times CPI variable used in the previous models ${ }^{16}$. The average elasticities reported

\footnotetext{
${ }^{16}$ This is a theoretical particularity of the AIDS and QUAIDS models (the translog model does not use income as an independent variable), related to the need that expenditure in all the goods whose demands are estimated
} 
were in all cases calculated using the following formula ${ }^{17}$ :

$\eta_{\mathrm{ii}}=-1+\frac{\beta_{\mathrm{ii}}}{\mathrm{s}_{\mathrm{i}}}$

and their corresponding p-values were obtained using the same method reported in footnote 13. The $\mathrm{R}^{2}$ coefficients obtained correspond to the seven equations of the model (that regress the expenditure shares of the first seven goods), plus the $\mathrm{R}^{2}$ coefficient of an equation for the expenditure share of tonic water. This last coefficient was obtained from running the system again, including the tonic water share equation and excluding the normal cola one.

The results produced by the translog, AIDS and QUAIDS models are relatively similar among themselves, and clearly worse than the ones generated by SEDS. The estimated elasticities display the right signs for seven out of the eight goods, but one of them (the one corresponding to the demand of light cola) is not statistically different from zero. The estimated demand elasticity whose sign is positive (light orange soda) is not statistically different from zero, either, and this is a feature that appears in the three alternative models. Many cross-price coefficients, moreover, display wrong (negative) sings, and this is also a pervasive feature of the three models under consideration. The corresponding $\mathrm{R}^{2}$ coefficients, finally, are not consistently higher than the ones produced by SEDS but, as expected, are always higher in the QUAIDS model, slightly lower in the AIDS model, and even lower in the translog model ${ }^{18}$. The system $\mathrm{R}^{2}$ coefficients generated by the three models, finally, are smaller than the one that corresponds to the SEDS model, although, for the AIDS and QUAIDS models, they are higher than the one produced by the SEDS with the adding-up restriction $^{19}$.

A last experiment that we performed is the one whose results appear on table 5. It consists of running alternative SEDS models with different aggregation levels for our commodities. Apart from our benchmark model with eight commodities, we also estimated a demand system for only four commodities. In it, we pooled together the normal cola and the

adds up to the total consumer's income. We nevertheless tried alternative regressions using EMAE*CPI as a measure of nominal income and the results did not vary a lot.

${ }^{17}$ In fact, this formula is exact only for the translog system, and it is one of the possible linear approximations for the own-price elasticity under the AIDS and QUAIDS models. For other alternative specifications, see Alston, Foster and Green (1994).

${ }^{18}$ This ranking has to do with the fact that the translog model can be seen as a particular case of AIDS (for which all $\beta_{i Y}=0$ ), and AIDS can be seen as a particular case of QUAIDS (for which all $\lambda_{i Y}=0$ ).

${ }^{19}$ In fact, the use of the systems' $\mathrm{R}^{2}$ coefficients to contrast the different models is only a relatively quick method to compare the results. For a more sophisticated analysis of this question, applied to the comparison of logarithmic and AIDS models, see Alston, Chalfant and Piggott (2002). 
normal orange soda to create a new composite commodity (good 1), and we did the same with the light cola and the light orange soda (good 2), the normal lime and grapefruit sodas (good 3 ), and the light lime soda and the tonic water (good 4). We further reduced the number of commodities to two, pooling together all the normal carbonated soft drinks (cola, lime, orange and grapefruit) to create a single composite commodity (good 1), and the light carbonated soft drinks (cola, lime, orange and tonic water) to create another composite commodity (good 2). On one side, we ended up with a system of four equations, with four own-price elasticities and six substitution elasticities. On the other side, we have a system of two equations with two own-price elasticities and one substitution elasticity.

\begin{tabular}{|c|c|c|c|c|c|c|}
\hline \multirow{3}{*}{$\begin{array}{l}\text { 5. COMPARISON OF DIF } \\
\text { Concept }\end{array}$} & \multirow{2}{*}{\multicolumn{2}{|c|}{$\begin{array}{c}\text { ERENT AGGREGATIOI } \\
\text { Eight commodities }\end{array}$}} & \multicolumn{2}{|c|}{ LEVEL RESULTS } & \\
\hline & & & Four com & nodities & Two com & nodities \\
\hline & Coefficient & P-value & Coefficient & P-value & Coefficient & P-value \\
\hline \multicolumn{7}{|l|}{ Own-price elasticities } \\
\hline Normal Cola $\left(\eta_{11}\right)$ & $-0,909439$ & 0,0000 & $-0,855681$ & 0,0000 & $-0,787979$ & 0,0000 \\
\hline Light Cola $\left(\eta_{22}\right)$ & $-0,962948$ & 0,0000 & $-0,921091$ & 0,0000 & $-0,894639$ & 0,0000 \\
\hline Normal Lime $\left(\eta_{33}\right)$ & $-0,966867$ & 0,0000 & $-0,930429$ & 0,0000 & $-0,787979$ & 0,0000 \\
\hline Light Lime $\left(\eta_{44}\right)$ & $-0,968006$ & 0,0000 & $-0,941505$ & 0,0000 & $-0,894639$ & 0,0000 \\
\hline Normal Orange $\left(\eta_{55}\right)$ & $-0,980961$ & 0,0000 & $-0,855681$ & 0,0000 & $-0,787979$ & 0,0000 \\
\hline Light Orange $\left(\eta_{66}\right)$ & $-1,020937$ & 0,0000 & $-0,921091$ & 0,0000 & $-0,894639$ & 0,0000 \\
\hline Grapefruit $\left(\eta_{77}\right)$ & $-1,019351$ & 0,0000 & $-0,930429$ & 0,0000 & $-0,787979$ & 0,0000 \\
\hline $\begin{array}{l}\text { Tonic Water }\left(\eta_{88}\right) \\
\text { Substitution elasticities }\end{array}$ & $-0,990164$ & 0,0000 & $-0,941505$ & 0,0000 & $-0,894639$ & 0,0000 \\
\hline NCola/LCola $\left(\sigma_{12}\right)$ & 0,991992 & 0,0000 & 0,953839 & 0,0000 & 0,945878 & 0,0000 \\
\hline NCola/NLime $\left(\sigma_{13}\right)$ & 0,999899 & 0,0000 & 0,972941 & 0,0000 & & \\
\hline NCola/LLime $\left(\sigma_{14}\right)$ & 0,986120 & 0,0000 & 0,959797 & 0,0000 & 0,945878 & 0,0000 \\
\hline LCola/NLime $\left(\sigma_{23}\right)$ & 0,994056 & 0,0000 & 0,979580 & 0,0000 & 0,945878 & 0,0000 \\
\hline LCola/LLime $\left(\sigma_{24}\right)$ & 0,960914 & 0,0000 & 0,941909 & 0,0000 & & \\
\hline NLime/LLime $\left(\sigma_{34}\right)$ & 0,976619 & 0,0000 & 0,970734 & 0,0000 & 0,945878 & 0,0000 \\
\hline
\end{tabular}

By looking at the results reported on table 5, we see that they respond to what economic theory predicts. When we include more products in the definition of a commodity, own-price elasticities become smaller in absolute value, and substitution elasticities become lower. This is because the redefined commodities are now poorer substitutes among themselves, and their demands must therefore be more inelastic than the ones estimated under a more precise commodity identification ${ }^{20}$. Table 5 also shows that all the estimated elasticities continue to display the expected signs and to be statistically different from zero at any possible level of significance.

\footnotetext{
${ }^{20}$ For a more detailed explanation of the economic logic of this, see Werden (1998).
} 


\section{Conclusions}

The main conclusions of our analysis can be summarized as follows:

a) The concept of elasticity of substitution is a good instrument to introduce symmetry in the estimation of a system of demand functions.

b) Relying on it, it is possible to build a linear system of logarithmic demand equations whose main coefficients are own-price elasticities and substitution elasticities, which is capable of incorporating the homogeneity, symmetry and, eventually, adding-up restrictions of consumer demand theory.

c) This system of equations, which we call SEDS, has to be estimated using instrumental variables (for example, through three-stage least square regressions), since its independent variables are functions of prices, income and expenditure shares, and these shares are endogenous variables in the demand equations.

d) Despite this endogeneity problem, SEDS has some advantages over the most common demand systems based on flexible functional forms (namely, translog, AIDS and QUAIDS models), since it is more efficient and it generates estimates that are easier to handle when we want to impose additional estimation restrictions.

e) It is also better than the less restricted logarithmic models, since it is capable of incorporating the symmetry property in a way that is more consistent with consumer theory. It is also less likely to generate coefficients with the wrong sings or coefficients that are not statistically significant.

f) All this makes SEDS particularly suitable for the estimation of demand systems of products that belong to the same industry, in which we can make the assumption that their demands are related among themselves but are basically independent from the demands of other goods.

g) With this idea in mind, we have applied the model to a database of weekly observations of prices and quantities of eight different carbonated soft drinks, in order to estimate the corresponding demand equations. We have obtained reasonable and highly significant estimates for all the own-price and substitution elasticities.

h) Using those estimated coefficients, we have also obtained reasonable estimates for the implied income and cross elasticities between the products.

i) Compared to other alternative estimation methodologies (unrestricted logarithmic, translog, AIDS, QUAIDS) the results of the SEDS model perform noticeably well, since the alternative methodologies always produce wrong sings for some elasticities, less 
significant coefficients, or a lower goodness of fit.

j) The model also performs well against different versions of itself. For example, when we aggregate the commodities to run a system with four equations and a system with two equations, own-price elasticities become smaller in absolute value, and substitution elasticities become lower.

\section{References}

Allen, R. G. D. (1938). Mathematical Analysis for Economists. London, Macmillan, 1938.

Alston, Julian; James Chalfant and Nicholas Piggott (2002). 'Estimating and Testing the Compensated Double-Log Demand Model”; Applied Economics, vol 34, pp 11771186.

Alston, Julian; Kenneth Foster and Richard Green (1994). 'Estimating Elasticities with the Linear Approximate Almost Ideal Demand System"; Review of Economics and Statistics, vol 76, pp 351-356.

Banks, James; Richard Blundell and Arthur Lewbel (1997). 'Quadratic Engel Curves and Consumer Demand"; Review of Economics and Statistics, vol 79, pp 527-539.

Barten, Anton (1993). 'Consumer Allocation Models: Choice of Functional Form”; Empirical Economics, vol 18, pp 129-158.

Blackorby, Charles and Robert Russell (1989). 'Will the Real Elasticity of Substitution Please Stand Up?"; American Economic Review, vol 79, pp 882-888.

Christensen, Laurits; Dale Jorgenson and Lawrence Lau (1975). 'Trascen dental Logarithmic Utility Function"; American Economic Review, vol 65, pp 367-383.

Dahr, Tirtha; Jean-Paul Chavas, Ronald Cotterill and Brian Gould (2005). "An Econometric Analysis of Brand-Level Strategic Pricing Between Coca-Cola Co. and PepsiCo.”; Journal of Economics and Management Strategy, vol 14, pp 905-931.

Deaton, Angus and John Muellbauer (1980). “An Almost Ideal Demand System”; American Economic Review, vol 70, pp 312-326.

Epstein, Roy and Daniel Rubinfeld (2002). 'Merger Simulation: A Simplifie d Approach with New Applications"; Antitrust Law Journal, vol 69, pp 883-919.

Frisch, Ragnar (1959). "A Complete Scheme for Computing All Direct and Cross Demand Elasticities in a Model with Many Sectors"; Econometrica, vol 27, pp 177-196.

McElroy, Marjorie (1977). 'Goodness of Fit for Seemingly Unrelated Regressions”; Journal of Econometrics, vol 6, pp 381-387. 
Moschini, Giancarlo and Anuradha Vissa (1993). 'Flexible Specifications of Mixed Demand Systems"; American Journal of Agricultural Economics, vol 75, pp 1-9.

Werden, Gregory (1998). 'Demand Elasticities in Antitrust Analysis”; Antitrust Law Journal, vol 66, pp 363-414.

\section{Acknowledgements}

I thank comments by Ricardo Bebczuk, Mariana Conte Grand, Mariana Marchionni,

Jorge Streb, and participants at seminars held at CEMA University and the National University of La Plata. 